\title{
Emotional Memory Formation Is Enhanced across Sleep Intervals with High Amounts of Rapid Eye Movement Sleep
}

\author{
Ullrich Wagner, ${ }^{1,2,3}$ Steffen Gais, ${ }^{2}$ and Jan Born ${ }^{1,2}$ \\ ${ }^{1}$ University of Bamberg, Department of Physiological Psychology, D-96045 Bamberg, Germany; ${ }^{2}$ Medical University of Lübeck, Department of \\ Clinical Neuroendocrinology, D-23538 Lübeck, Germany
}

\begin{abstract}
Recent studies indicated a selective activation during rapid eye movement (REM) sleep of the amygdala known to play a decisive role in the processing of emotional stimuli. This study compared memory retention of emotional versus neutral text material over intervals covering either early sleep known to be dominated by nonREM slow wave sleep (SWS) or late sleep, in which REM sleep is dominant. Two groups of men were tested across 3-h periods of early and late sleep (sleep group) or corresponding retention intervals filled with wakefulness (wake group). Sleep was recorded polysomnographically. Cortisol concentrations in saliva were monitored at acquisition and retrieval testing. As expected, the amount of REM sleep was about three times greater during late than during early retention sleep, whereas a reversed pattern was observed for SWS distribution $(P<0.001)$. Sleep improved retention, compared with the effects of wake intervals $(P<0.02)$. However, this effect was substantial only in the late night $(P<0.005)$, during which retention was generally worse than during the early night $(P<0.02)$. Late sleep particularly enhanced memory for emotional texts. This effect was highly significant in comparison with memory for neutral texts $(P<0.01)$ and in comparison with memory after late and early wake intervals $(P<0.001)$. Cortisol concentration differed between early and late retention intervals but not between sleep and wake conditions. Results are consonant with a supportive function of REM sleep predominating late sleep for the formation of emotional memory in humans.
\end{abstract}

It is well established that sleep has a facilitating effect on memory formation in animals and humans (e.g., Jenkins and Dallenbach 1924; Smith 1985, 1995; Stickgold et al. 2000). However, the physiological mechanisms of this effect are still unclear. Specifically, there is an ongoing controversy concerning the differential contribution of rapid eye movement (REM) sleep and slow wave sleep (SWS) to memory consolidation. In particular, human studies provided mixed results, some indicating a beneficial effect of REM sleep on memory (Empson and Clarke 1970; Lewin and Glaubman 1975; Tilley and Empson 1978) whereas others suggested SWS to be critical for memory formation (Yaroush et al. 1971; Barrett and Ekstrand 1972; Fowler et al. 1973; Ekstrand 1977). The divergent outcomes appear to reflect differences in the methods used for investigating memory formation during sleep and in the type of memory examined. The most commonly used approach in the study of sleepassociated memory formation is the REM sleep deprivation paradigm, in which subjects are awakened whenever polysomnographic recordings indicate signs of REM sleep. In control conditions, awakenings are induced in nonREM

${ }^{3}$ Corresponding author.

E-MAIL wagner@kfg.mu-luebeck.de; FAX 49-451-5003640.

Article and publication are at www.learnmem.org/cgi/doi/ $10.1101 / \mathrm{lm} .36801$. sleep. Yet the REM sleep-deprivation paradigm has been subject to profound criticism (Horne and McGrath 1984; Vertes and Eastman, in press). Compared with other sleep stages, frequent arousal from REM sleep induces serious emotional and cognitive disturbances. These disturbances impair performance at the time of memory retrieval, which is tested usually in the morning after the sleep period, and thus hinder any conclusion with regard to the role of REM sleep for the consolidation process. In a completely different approach, Ekstrand and coworkers compared memory retention following 4 -h periods of undisturbed sleep covering either the first or the second half of the night (Yaroush et al. 1971; Barrett and Ekstrand 1972; Fowler et al. 1973; Ekstrand 1977). The paradigm allows dissociation of the effects of SWS and REM sleep because, in human sleep, the first half of the night is characterized by a high percentage of SWS, whereas REM sleep prevails in the second half. Because it leaves the normal sleep architecture during the relevant sleep intervals intact, this approach seems to be advantageous over the REM sleep-deprivation paradigm and, hence, was also adopted in this experiment.

Memory is not uniform but is comprised of several subsystems, which are represented by different brain structures and are differentially influenced by sleep stages. Using the method by Ekstrand and coworkers (described above),

LEARNING \& MEMORY 8:112-119 @ 2001 by Cold Spring Harbor Laboratory Press ISSN1072-0502/01 \$5.00

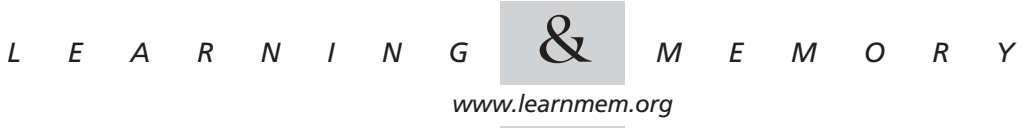


Plihal and Born (1997, 1999) compared effects of early sleep (dominated by SWS) and late sleep (dominated by REM) on declarative and procedural memory consolidation. In these studies, early sleep was found to selectively improve consolidation of declarative tasks (paired-associate words, spatial rotation) but did not improve memory for the procedural tasks of the studies (mirror tracing, word stem priming).

Declarative memory is known to rely essentially on the hippocampus and adjacent structures (e.g., Squire 1992). However, within the declarative memory system, processing of emotional materials differs from that of neutral material. A superior retention of emotional over neutral stimuli has been uniformly shown in healthy humans (e.g., Bradley et al. 1992; Burke et al. 1992; Cahill et al. 1994; Cahill and McGaugh 1998) and amnesic patients (Hamann et al. 1997). In addition to the hippocampal formation, declarative memory for emotional materials probably relies essentially on the amygdala (Cahill and McGaugh 1998; Roozendaal 2000). The amygdala has been shown to modulate memory processing in other brain regions including the hippocampus (Cahill and McGaugh 1998; McGaugh et al. 1996; Roozendaal 2000). Specifically, several studies demonstrated a contribution of the amygdala selectively to the formation of emotional but not neutral declarative memories (Markowitsch et al. 1994; Cahill et al. 1995, 1996; Adolphs et al. 1997, 2000; Hamann et al. 1999).

Using positron emission tomography (PET), studies in humans have indicated an increased activation of the amygdala selectively during REM sleep (Maquet et al. 1996; Nofzinger et al. 1997). A close relation of REM sleep to emotional processing has been also suggested by studies of dreams, which appear to be more vivid and emotionally loaded during this sleep stage, whereas dreams occurring during other sleep stages, if reported at all, have a more thought-like cognitive character (Foulkes 1962). Moreover, affective disorders such as depression are typically characterized by distinct changes in REM sleep (for overviews see, e.g., Benca et al. 1992; Thase 1998). With this background, we assumed that REM sleep plays a specific role for emotional memories. Specifically, we hypothesized that late sleep, in which REM sleep predominates, facilitates the consolidation of emotional declarative memories more than that of neutral memories. No such differential effect was expected for early sleep comprising little REM sleep. The issue of whether REM sleep is specifically related to memory formation for emotional material has not yet been investigated except in studies using the REM sleep-deprivation paradigm (Grieser et al. 1972; Cartwright et al. 1975).

Here, we compared declarative memory formation for neutral and emotionally arousing materials during periods of early and late sleep. Subjects had to read and memorize an emotional text and a neutral text before 3-h retention periods filled either with SWS-rich early or REM sleep-rich late sleep. In a control group, subjects stayed awake during corresponding 3-h retention intervals. Free recall was tested immediately after learning to determine performance at acquisition, and after the 3-h retention intervals (retrieval testing). Because glucocorticoids are known to be potent modulators of encoding, consolidation, and retrieval of declarative memories (Kirschbaum et al. 1996; de Quervain et al. 1998; Newcomer et al. 1999; Plihal et al. 1999; Roozendaal 2000) and because early and late nocturnal sleep periods differ with respect to the release of glucocorticoids from the pituitary-adrenal system, we also monitored cortisol concentrations in saliva before and after the retention intervals.

\section{RESULTS}

\section{Sleep and Cortisol}

Sleep architecture differed substantially between early and late sleep retention periods with respect to SWS and REM sleep (Table 1 ). SWS covered $28.00 \%$ of early retention sleep but only $10.25 \%$ of late retention sleep $[F(1,11)=38.07, P<0.001]$. Conversely, REM sleep covered on average $10.15 \%$ of early and $31.23 \%$ of late retention sleep $[F(1,11)=66.59, P<0.001]$. Differences in the other sleep stages were not significant. Also, sleep during the early sleep retention interval was comparable with that obtained during the early night before learning in the late sleep condition $(P>0.39$ for all parameters).

As expected, saliva cortisol concentrations were substantially lower for the early than late retention condition in both the experimental sleep group $(0.016 \pm 0.006$ versus $0.251 \pm 0.046 \mu \mathrm{g} / \mathrm{dL}, P<0.001)$ and the wake control group $(0.044 \pm 0.017$ versus $0.369 \pm 0.062 \mu \mathrm{g} / \mathrm{dL}, P<0.001)$. Differences in cortisol concentration for corresponding retention conditions between the sleep group and the wake control group did not reach significance $(P>0.15$ and $P>0.13$, respectively).

Table 1. Sleep Data

\begin{tabular}{|c|c|c|c|c|c|}
\hline \multirow[b]{2}{*}{ Sleep parameter } & \multicolumn{2}{|c|}{$\begin{array}{l}\text { Early retention } \\
\text { sleep }\end{array}$} & \multicolumn{2}{|c|}{$\begin{array}{l}\text { Late retention } \\
\text { sleep }\end{array}$} & \multirow[b]{2}{*}{$F(1,11)$} \\
\hline & Mean & SEM & Mean & SEM & \\
\hline Sleep onset (min) & 30.38 & 8.87 & 26.17 & 5.16 & 0.27 \\
\hline Sleep time (min) & 184.83 & 2.59 & 184.50 & 5.26 & 0.00 \\
\hline Wake $(\%)$ & 0.26 & 0.16 & 0.64 & 0.35 & 1.06 \\
\hline $\mathrm{S} 1(\%)$ & 5.54 & 1.08 & 6.28 & 1.58 & 0.27 \\
\hline $\mathrm{S} 2(\%)$ & 56.03 & 3.71 & 51.59 & 3.40 & 1.59 \\
\hline SWS (\%) & 28.00 & 3.24 & 10.25 & 2.47 & $38.07^{* * *}$ \\
\hline REM (\%) & 10.15 & 1.62 & 31.23 & 2.06 & $66.59 * * *$ \\
\hline
\end{tabular}

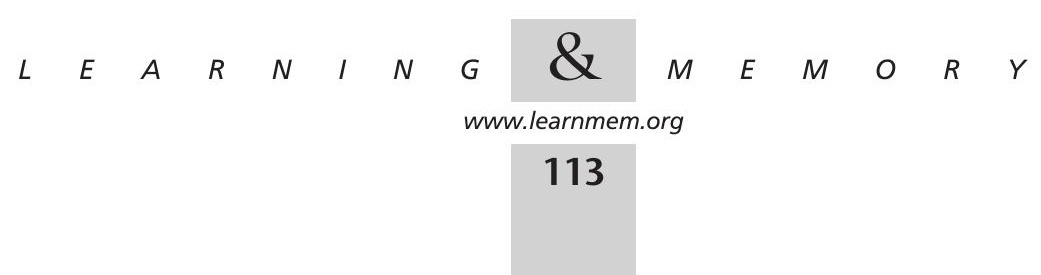




\section{Memory Measures}

Table 2 shows performance for the learning phase before the retention interval and for retrieval testing thereafter together with results from pairwise statistical comparisons. In general, recall of emotional texts was clearly superior to that of neutral texts both at learning $[50.0 \%$ of the emotional texts versus $33.0 \%$ of the neutral texts correctly recalled; $F(1,21)=82.6, P<0.0001]$ and at retrieval testing [42.1\% versus $27.2 \% ; F(1,21)=62.7, P<0.0001$ ]. Performance at learning was comparable before sleep and wake retention intervals $(P>0.46)$, and there were also no differences in performance at learning between early and late retention conditions $(P>0.75)$.

The focus of analysis was memory retention over the relevant time intervals, as indicated by the percentage of content words recalled at retrieval, with performance at learning set to $100 \%$. In general, retention over the early half of the night was superior to that over the late half of the night $[F(1,21)=7.25, P<0.02]$. Also, retention over intervals filled with sleep was better than over intervals filled with wakefulness $[F(1,21)=6.77, P<0.02]$. However, memory for neutral material benefited less from sleep than did memory for emotional material $[F(1,21)=5.56$, $P<0.05$, for Sleep $\times$ Emotionality interaction]. In fact, separate analyses for emotional and neutral text retention indicated that only the former but not the latter benefited significantly from sleep $[F(1,21)=24.49, \quad P<0.001$ and $F(1,21)=0.30, P>0.58$, respectively, for main effect of sleep].

A differential consolidation of emotional versus neutral texts was revealed when first and second night halves were analyzed separately. While these analyses failed to indicate any effects of early sleep, they confirmed a strongly enhanced retention of texts across late sleep as compared to late wakefulness $[F(1,21)=10.29, P<0.005]$, with this im- proving influence of late sleep being particularly pronounced for emotional texts $[F(1,21)=4.41, P<0.05$, for Sleep $\times$ Emotionality interaction]. As depicted in Figure 1, retention of emotional texts over late sleep was strongly enhanced in comparison to the corresponding late wake condition $(P<0.001$; see also Table 2$)$ as well as in comparison to retention of neutral texts over the late sleep interval $(P<0.01)$. Moreover, an additional comparison with retention of emotional texts during the early wake condition was likewise significant $(P<0.001)$. Differential sleep effects were also revealed regarding emotional texts separately. Here, memory retention benefited more from late sleep than from early sleep $[F(1,21)=4.41, P<0.05$, for Sleep $\times$ Nighthalf interaction] .

\section{Text Ratings and Attention}

Immediately after reading a text, subjects rated the text on 11 scales $(-3$ to +3$)$. Consistent with the results of SchürerNecker (1994), emotional compared to neutral texts were scored higher on the scales (translated from German) startling-harmless (mean \pm SEM for emotional texts: $2.26 \pm 0.14$, for neutral texts: $-2.04 \pm 0.20$ ), arousingboring $(1.15 \pm 0.16$ versus $-2.07 \pm 0.17)$, emotional-neutral $(1.57 \pm 0.24$ versus $-1.76 \pm 0.26)$, important-unimportant $(0.72 \pm 0.19$ versus $-1.93 \pm 0.19)$, and interesting-uninteresting $[1.30 \pm 0.20$ versus $-1.78 \pm 0.24 ; \quad F(1,22)>81, \quad P<0.0001$, for respective comparisons]. Parallel differences between emotional versus neutral texts for the scales positivenegative $(-2.04 \pm 0.16$ versus $-0.07 \pm 0.18)$, comprehensible-incomprehensible $(2.11 \pm 0.20$ versus $-0.52 \pm 0.26)$, vivid-abstract $(2.04 \pm 0.17$ versus $-0.17 \pm 0.28)$, difficulteasy $(-1.07 \pm 0.24$ versus $0.83 \pm 0.21)$, and amusingserious $(-1.98 \pm 0.21$ versus $0.67 \pm 0.27)$ were also significant but less pronounced $[F(1,22)>18, P<0.01]$. The difference on the scale familiar-unfamiliar was not signifi-

Table 2. Memory Measures for Neutral and Emotional Texts

\begin{tabular}{|c|c|c|c|c|c|c|c|}
\hline & & \multicolumn{3}{|c|}{ Early retention interval } & \multicolumn{3}{|c|}{ Late retention interval } \\
\hline & & $\begin{array}{c}\text { Sleep } \\
\text { mean } \pm \text { SEM }\end{array}$ & $\begin{array}{c}\text { Wake } \\
\text { mean } \pm \text { SEM }\end{array}$ & $F(1,21)$ & $\begin{array}{c}\text { Sleep } \\
\text { mean } \pm \text { SEM }\end{array}$ & $\begin{array}{c}\text { Wake } \\
\text { mean } \pm \text { SEM }\end{array}$ & $F(1,21)$ \\
\hline \multicolumn{8}{|c|}{ Memory for neutral texts } \\
\hline Learning & Recall of content words & $30.63 \pm 2.50$ & $33.33 \pm 3.96$ & 0.35 & $35.26 \pm 1.91$ & $32.63 \pm 3.10$ & 0.55 \\
\hline Retrieval & Recall of content words & $27.90 \pm 3.04$ & $29.55 \pm 3.37$ & 0.13 & $27.91 \pm 1.93$ & $23.28 \pm 2.81$ & 1.90 \\
\hline Retention & Percent of learning & $89.64 \pm 4.30$ & $89.68 \pm 4.14$ & 0.00 & $79.20 \pm 3.85$ & $73.36 \pm 6.17$ & 0.67 \\
\hline \multicolumn{8}{|c|}{ Memory for emotional texts } \\
\hline Learning & Recall of content words & $50.38 \pm 3.21$ & $50.03 \pm 4.16$ & 0.01 & $49.39 \pm 2.38$ & $49.85 \pm 3.86$ & 0.01 \\
\hline Retrieval & Recall of content words & $44.75 \pm 3.30$ & $40.21 \pm 3.79$ & 0.83 & $46.13 \pm 2.50$ & $36.67 \pm 3.87$ & $4.37^{*}$ \\
\hline Retention & Percent of learning & $89.34 \pm 4.07$ & $80.15 \pm 2.83$ & 3.31 & $93.27 \pm 1.89$ & $72.30 \pm 2.59$ & $43.82^{* * *}$ \\
\hline
\end{tabular}

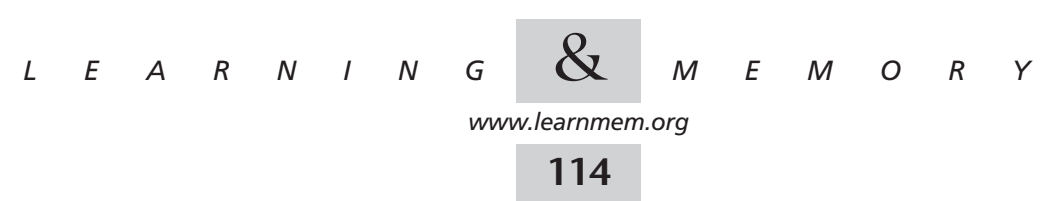




\section{Mernory retention}

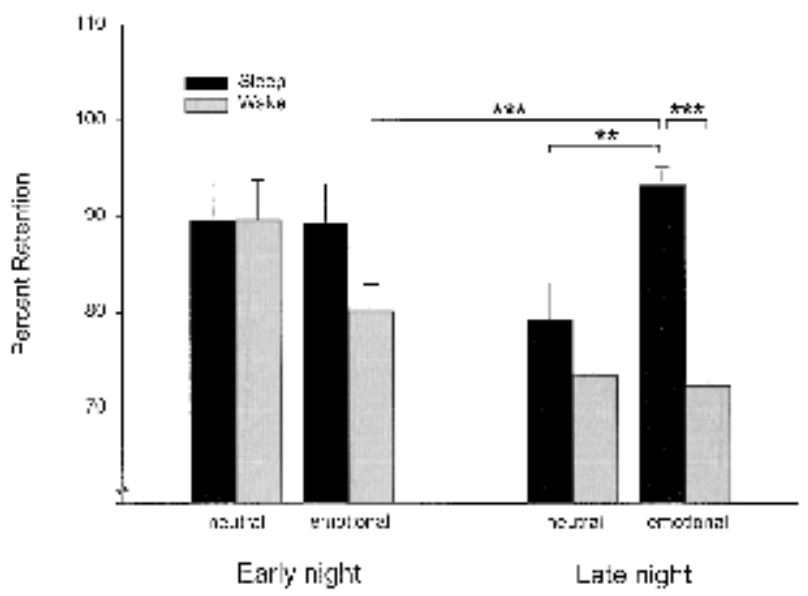

Figure 1 Memory retention across the early (left panel) and late night (right panel) for neutral and emotional texts over 3-h retention intervals filled with sleep (black) or wakefulness (grey). Retention is indicated by the percentage of content words correctly recalled at retrieval testing with reference to performance at learning before the retention interval. Note the superior retention of emotional texts after late sleep compared to late wakefulness and to retention of neutral texts. In comparison with early night conditions, retention of emotional texts during late sleep was also significantly superior to that during early wakefulness. ${ }^{* * *} P<0.001$, ${ }^{* *} P<0.01$.

cant. Texts were generally rated somewhat more arousing and more comprehensible in the middle of the night than in the evening ( $P<0.05$ for the effect of Nighthalf).

Attentional capacity was measured immediately before each learning and retrieval phase by the time needed to solve arithmetic tasks. (The number of errors was too small to allow statistical analysis.) Greater attentional capacity was found at retrieval testing than at learning $(P<0.05)$. However, there was no significant difference between early and late conditions with respect to attention at learning and at retrieval testing $(P>0.18)$.

\section{DISCUSSION}

In line with many previous studies (e.g., Jenkins and Dallenbach 1924; Fowler et al. 1973; Ekstrand 1977; Scrima 1982; Koulack 1997; Plihal and Born 1997, 1999), this study confirmed that sleep in general facilitates the retention of declarative memories when compared with periods of wakefulness. Whether this effect of sleep represents a true improvement of consolidation rather than a protection against stronger deterioration of memories during the wake state was not the issue of this study and cannot be answered here. These data are conspicuous in that they demonstrate a differential effect of sleep on memory depending on whether neutral or emotionally arousing material was to be stored. Memory for emotional material was strongly en- hanced after a period of late retention sleep in which REM sleep was predominant, and this enhancement was highly significant in comparison to retention over a corresponding period of wakefulness as well as in comparison to retention of neutral material over the same late sleep interval. No such effects were found for early sleep. Moreover, separate analyses of emotional texts indicated a significantly greater retention benefit from late than early sleep, compared to wakefulness. Because late sleep is dominated by REM sleep, our findings agree with the view proposed in earlier studies using REM sleep deprivation-that this sleep stage plays a crucial role in the formation of emotional memories (Grieser et al. 1972; Cartwright et al. 1975).

Ratings obtained after reading each text confirmed that emotional texts were on a subjective level more startling and arousing and were judged more emotional and more negative than neutral texts. Also, emotional texts were rated more interesting and important, more comprehensible, more vivid, and less difficult. The latter differences in ratings probably reflect a type of 'halo' effect and, therefore, may be considered a necessary consequence of the features inherent to emotional texts (Schürer-Necker 1994). Alternatively, the respective scales could be considered to pertain to characteristics that can be dissociated from the emotionality of the text. Although unlikely, in this case we cannot exclude a contribution of these factors to retention of emotional texts. In this context, it is also to be noted that the emotional texts ("Murderer," "Paraplegia") had a somewhat more narrative character than the neutral texts, which were more descriptive ("Bronze," "Fashion"). This difference might have also contributed to differences in encoding levels as well as in ratings, although again, such differences are hard to be dissociated from those in emotionality.

Consistent with numerous previous studies (e.g., Bradley et al. 1992; Burke et al. 1992; Cahill et al. 1994, 1996; Cahill and McGaugh 1998), memory for emotionally arousing material was generally superior to that of neutral material when tested at learning before the retention interval as well as at retrieval testing thereafter. Thus, emotionality apparently activates mechanisms strengthening associative connections already at the stage of encoding (Cahill et al. 1996; Hamann et al. 1999). It is to be considered in this context that the number of content words initially learned, being distinctly greater for emotional than neutral texts, could have also differentially affected subsequent retention. To control for this confounding factor, recall after the retention periods was determined here relative to the performance before this period at initial learning (i.e., as percentage of learning values). Nevertheless, it can be argued that this transformation does not exclude any kind of effect of initial learning performance on retention. However, a supplementary analysis (ANOVA) on the retention of neutral texts performed after a split-half division of the group into good and poor learners did not reveal any hint at an

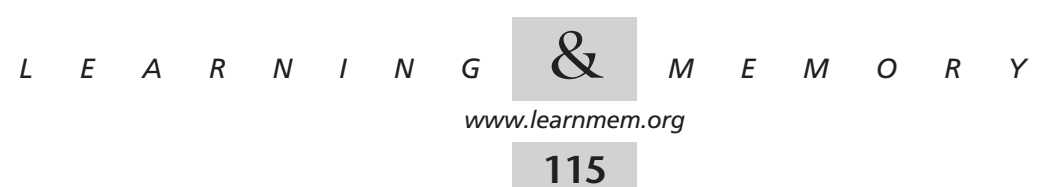


essential contribution of initial learning performance to retention $(P>0.24$, for the respective effects of the factor learning performance). Notably, essentially the same results were found when a parallel analysis was run on emotional texts $(P>0.29)$. This negative outcome argues against the view ascribing differential effects of sleep on the retention of emotional versus neutral texts to the differences in original encoding of the materials.

An important finding is that retention was distinctly better across the early than late night half, regardless of whether subjects slept or were kept awake. This pattern points to a circadian influence on retention, which appears to be independent of encoding, as recall performance at learning before the retention intervals was comparable between the early and late retention conditions. Also, an effect secondary to changes in attentional capacity can be excluded because attention testing did not indicate any difference in performance between the early and late condition, neither before nor after the respective retention intervals. The decrease in retention capabilities across the night agrees with previous studies indicating, likewise, particularly poor levels of memory performance during the early morning hours (Tilley and Warren 1983; Koulack 1997). However, examining declarative memory for word pairs, a previous experiment in our laboratory did not confirm circadian changes in retention across the night (Plihal and Born 1997). It is difficult to integrate these inconsistencies. A comparison of the materials used in the various studies leads to the speculation that circadian influences are more likely to emerge with the more complex texts to be remembered than with the simple word pairs. However, complexity of the material is also a factor sensitive to the effects of sleep stages independent of circadian influences, as consolidation for complex and meaningful materials has been shown to benefit more from REM sleep than from SWS (Empson and Clarke 1970; Tilley and Empson 1978; Scrima 1982; Smith 1995).

The distinct circadian effect observed here might also be related to the unexpected finding that early sleep failed to improve memory not only for emotional but also for neutral texts. This finding diverges from earlier experiments with neutral material where a clear advantage for recall of declarative memory after early sleep as compared to wakefulness was found (Yaroush et al. 1971; Barrett and Ekstrand 1972; Fowler et al. 1973; Plihal and Born 1997, 1999). However, again, most of these former studies employed less complex tasks of paired-associate learning that, compared to learning of text material, require less semantic integration. Thus, here the retention rate of the neutral texts across the early night half turned out to be remarkably high even in the wake condition, and this high retention level during the early night may have prevented the occurrence of an additive effect of sleep on memory for these texts. Furthermore, it could be argued that the generally high retention rate during the early night also prevented a selective improvement of emotional memory during this period of sleep. Comparing changes across the early and late night half (Fig. 1), it is possible that memories encoded in the late condition are generally more labile than those in the early condition and that sleep prevents forgetting of emotional memories more than forgetting of neutral memories. This alternative interpretation relies on the assumption of ceiling effects in the first night half that mask the emergence of sleep effects. Whether ceiling effects are, in fact, present in the early night half cannot be decided on the basis of the present data. However, the increase in retention of emotional texts during late sleep was found to be highly significant not only in (pairwise) comparison with the late wake but also with the early wake condition $(P<0.001)$. This supports a causative role of late sleep for this enhancement, even in the presence of ceiling effects.

The disproportional facilitation of memory for emotional compared to neutral text materials encountered selectively during late sleep is consonant with the notion of a critical involvement of REM sleep in the formation of emotional memories, because this sleep stage prevails during late sleep. Human PET studies have shown that REM sleep is characterized by pronounced activation of the amygdala (Maquet et al. 1996; Nofzinger et al. 1997). Also, cholinergic activation of the central amygdaloid nucleus was found to facilitate REM sleep occurrence in cats (Calvo et al. 1996). In humans, the amygdala is well known to play a central role in the formation of memories for emotionally arousing material (Markowitsch et al. 1994; Cahill et al. 1995; Adolphs et al. 1997, 2000; Cahill and McGaugh 1998). With this background, it is tempting to relate the particular benefit for emotional memory from late retention sleep to enhanced amygdalar activity accompanying the extended REM sleep epochs of this period. This conclusion is also supported by several other studies in animals and humans suggesting that patterns of emotional arousal induced during learning become reactivated during REM sleep, thereby strengthening memory traces and connectivity within respective neural networks (Goodenough et al. 1975; Hennevin et al. 1998; Maho and Hennevin 1999). In the case of emotional declarative memories, this influence could be mediated via modulatory influences of the amygdala on the hippocampal memory system (McGaugh et al. 1996; Hamann et al. 1999; Roozendaal 2000).

Apart from the predominance of REM sleep, late sleep is characterized by a number of concomitant changes that could also affect emotional memory formation. Most important in this context appears to be the release of cortisol, which is enhanced during the late night as compared to the early night and was found to profoundly influence memory formation (e.g., Cahill and McGaugh 1998; Roozendaal 2000). In humans, the effect of glucocorticoids was an impairing one in all cases (e.g., Kirschbaum et al. 1996; New-

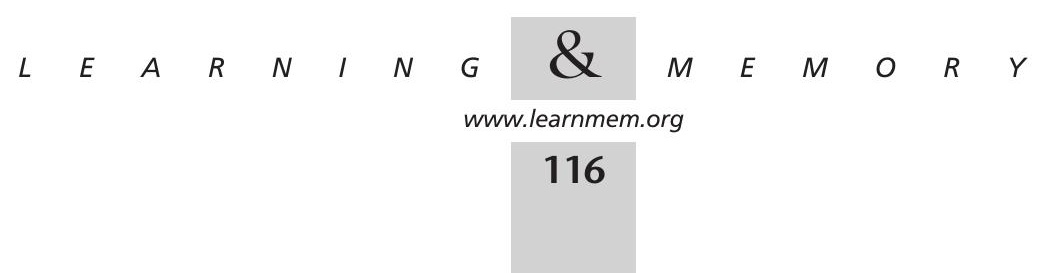


comer et al. 1999), although to the best of our knowledge, effects of glucocorticoids specifically on emotional memories have not yet been examined. Interestingly, in rats, injection of glucocorticoids into the basolateral amygdala (Roozendaal and McGaugh 1997) as well as into the nucleus of the solitary tract (Roozendaal et al. 1999), which projects to the basolateral amygdala, improved memory for an inhibitory avoidance task. These findings point to a selective beneficial effect of glucocorticoids on storage of emotionally arousing materials. However, because cortisol concentrations in this study did not differ substantially between the late sleep and the late wake condition, enhanced cortisol release during the late night per se is not sufficient for explaining the enhanced retention of emotional texts selectively across late sleep. Rather, cortisol release could interact with specific mechanisms active during late REM sleep to induce this memory facilitation. The exact role of glucocorticoids remains to be determined.

\section{MATERIALS AND METHODS}

\section{Subjects}

Twenty-three healthy men aged 20-30 yr (mean $24.2 \mathrm{yr}$ ) without a history of sleep disturbances participated in the experiment. They were nonsmoking students at the University of Bamberg and were paid for participation. They did not take any medication. Subjects were acclimated to the experimental sleep condition by spending an adaptation night in the sleep laboratory, which included the placement of electrodes. The men were instructed to get up before $0700 \mathrm{~h}$ on experimental days and not to take any naps during these days. The experiment was approved by the local ethics committee. Subjects gave written informed consent before participation.

\section{Design and Procedure}

Figure 2 illustrates the design of the study. Subjects were allocated to an experimental sleep group $(n=12)$ or a wake control group $(n=11)$. Each subject was tested on two nights separated by an interval of $\sim 1 \mathrm{wk}$ (5-10 d). On one of the occasions, retention over the first half of the night was tested, and on the other the second half of the night was investigated, with the order of conditions balanced across subjects. Subjects of the experimental sleep group tested over the first half of the night (early sleep retention) reported to the laboratory at $2130 \mathrm{~h}$ and, after placement of electrodes for sleep recordings, learned the texts between $2215 \mathrm{~h}$ and $2300 \mathrm{~h}$. Then lights were turned off to enable sleep. Three hours after sleep onset, subjects were awakened as soon as sleep stages 1 or 2 occurred. Awakening from SWS or REM sleep was avoided because it can influence subsequent memory performance (Stones 1977). Fifteen minutes after awakening, retrieval was tested. When tested over the second half of the night (late sleep retention), subjects reported to the laboratory at $2230 \mathrm{~h}$. After sleep recordings had been prepared, lights were turned off at $2300 \mathrm{~h}$ to enable sleep. After $3 \mathrm{~h}$ of sleep, subjects were awakened from stage 1 or 2 sleep, and 15 min later the learning phase began (lasting from about $0215 \mathrm{~h}$ to $0300 \mathrm{~h}$ ). Thereafter, they had another 3 -h period of retention sleep. Fifteen minutes after awakening from stage 1 or 2 sleep, retrieval was tested (about 0615-0700 h).

For the subjects of the wake control group, the procedure was exactly the same as for the experimental sleep group, except that the corresponding 3-h retention intervals were filled with wakefulness instead of sleep. In the periods of wakefulness, subjects were engaged in standardized activities (playing simple dice games, watching a video requiring little cognitive involvement) to prevent rehearsal of learned materials and to keep them awake at a low arousal level. Cortisol was measured in saliva immediately before and after each retention interval.

\section{Memory Testing}

In the learning phase before the retention interval, subjects learned two experimental texts (a neutral and an emotional text) and two further texts. The latter texts were presented before and after the experimental texts, respectively, to serve as primacy and recency buffers. The order of presentation of the experimental texts within a session and the order of parallel versions on the two test occasions of a subject were balanced across subjects.

The subject was instructed to read the texts (printed on a sheet of paper) thoroughly and to memorize as many details as possible for later recall. He was informed that recall was tested immediately after reading and after the 3-h retention interval. After reading, subjects rated each text on 7-point scales $(-3$ to +3$)$ with regard to the following dimensions: comprehensible-incomprehensible, interesting-uninteresting, difficult-easy, neutral-emotional, harmless-startling, important-unimportant, vivid-abstract, amusing-serious, boring-interesting, familiar-unfamiliar, and positive-negative. Thereafter, immediate free recall was tested to determine the original encoding level. Subjects were asked to write down the previously read text as exactly as possible, ideally in a literal way. No time limit was set to assess all accessible memories. Retrieval testing after the retention interval was performed in the same manner. No restriction was given concerning the order of text retrieval, and again, no time limit was set. The only constraint was that information from different texts had to be written on separate sheets of paper.

At the beginning of each learning and retrieval phase, a short attention test was presented, consisting of 60 simple arithmetical tasks (addition and subtraction). The tasks had to be solved as quickly and accurately as possible.

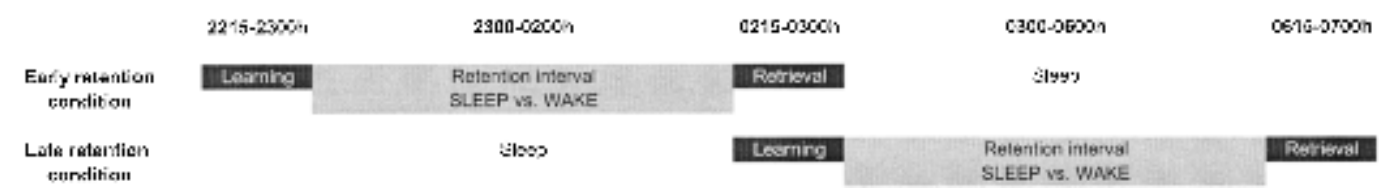

Figure 2 Study design. Subjects were tested on two nights (early versus late retention condition), with the order balanced across subjects. On the early retention condition, learning of the texts took place between $2215-2300 \mathrm{~h}$, followed by a retention interval of $\sim 3 \mathrm{~h}$. On the late retention condition, subjects first slept between 2300-0200 h (to "consume" SWS). Learning took place between 0215-0300 h, followed by a 3-h retention interval with subsequent retrieval testing. The experimental sleep group slept during the retention interval, and retrieval was tested $15 \mathrm{~min}$ after awakening. The control group remained awake in the retention intervals.

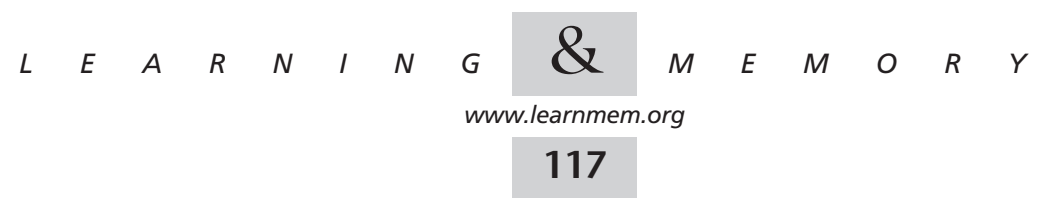




\section{Text Materials}

Standardized texts (adopted from Schürer-Necker 1994) were used, the emotionality of which had been characterized by both subjective and physiological (electrodermal) measures. The highly emotional texts were "Paraplegia" and "Murderer". Paraplegia was a report of a paraplegic man describing frankly his handicapped situation including sexual problems. Murderer described in detail the killing procedures of a child murderer. Of the two neutral texts, one dealt with the manufacture of a bronze sculpture (Bronze), and the other with clothing presented on a fashion show (Fashion). Texts were roughly matched in length (between 202 and 255 words). Expressed in the number of content words (nouns, adjectives, and verbs), which was used for memory assessment here, the average length was 95.0 for the neutral texts (Bronze: 78, Fashion: 112) and 94.5 for the emotional texts (Murderer: 94, Paraplegia: 95). Four additional neutral texts were chosen as primacy and recency buffers.

\section{Recordings and Data Analysis}

Sleep was assessed by standard polysomnography, including electroencephalogram (EEG), elecrooculogram (EOG), and electromyogram (EMG). Recordings were scored off-line by two experienced researchers according to the criteria of Rechtschaffen and Kales (1968). For each 3-h sleep interval, total sleep time, sleep onset latency, and absolute as well as relative time spent in sleep stages $1,2,3,4$, and REM sleep were determined. SWS time was calculated as the sum of time in sleep stages 3 and 4. Cortisol was sampled with the Salivette sampling device (Sarstedt) and kept at $-20^{\circ} \mathrm{C}$ until radioimmunometric assay. The two cortisol concentrations obtained immediately before and after each retention interval were averaged to estimate cortisol release during the retention interval.

Assessment of memory performance was based on the number of content words (nouns, adjectives, and verbs) correctly recalled. Validity of this measure was confirmed by comparisons to other measures (including complex measures relying on propositions and semantic relations between words) in previous experiments (Schürer-Necker 1994). Apart from words exactly reproduced, synonyms were also considered correct, as well as word type transitions (e.g., from noun to adjective) if both words were derived from the same word stem. At learning and at retrieval testing, recall performance was determined by the percentage of text content words correctly recalled. To assess memory retention reflecting consolidation over the retention interval, the percentage of content words recalled at retrieval was calculated with reference to performance at learning, which was set to $100 \%$. (Analyses based on absolute instead of relative memory measures yielded essentially the same results and, therefore, are not reported here.)

Statistical analysis of memory measures was performed by analyses of variance (ANOVA) with one group factor (Sleep versus Wake) and two repeated measures factors (Nighthalf: early versus late retention, and Emotionality: neutral versus emotional text). Pairwise contrasts were specified by $F$-tests. ANOVA with subsequent pairwise comparisons was also used to determine differences in sleep, cortisol, and ratings among conditions. Degrees of freedom were corrected after Greenhouse-Geisser. The significance level was set to $\alpha=0.05$.

\section{ACKNOWLEDGMENTS}

We thank A. Otterbein, J.-H. Klein, C. Zinke, and S. Baxmann for their skilled technical assistance. The publication costs of this ar- ticle were defrayed in part by payment of page charges. This article must therefore be hereby marked "advertisement" in accordance with 18 USC section 1734 solely to indicate this fact.

\section{REFERENCES}

Adolphs, R., Cahill, L., Schul, R., and Babinsky, R. 1997. Impaired declarative memory for emotional material following bilateral amygdala damage in humans. Learn. Mem. 4: 291-300.

Adolphs, R., Tranel, D., and Denburg, N. 2000. Impaired emotional declarative memory following unilateral amygdala damage. Learn. Mem. 7: 180-186.

Barrett, T.R. and Ekstrand, B.R. 1972. Effect of sleep on memory. 3. Controlling for time-of-day effects. J. Exp. Psychol. 96: 321-327.

Benca, R.M., Obermeyer, W.H., Thisted, R.A., and Gillin, J.C. 1992. Sleep and psychiatric disorders: A meta-analysis. Arch. Gen. Psychiatry 49: 651-668.

Bradley, M.M., Greenwald, M.K., Petry, M.C., and Lang, P.J. 1992. Remembering pictures: Pleasure and arousal in memory. J. Exp. Psychol. Learn. Mem. Cogn. 18: 379-390.

Burke, A., Heuer, F., and Reisberg, D. 1992. Remembering emotional events. Mem. Cognit. 20: 277-290.

Cahill, L. and McGaugh, J.L. 1998. Mechanisms of emotional arousal and lasting declarative memory. Trends Neurosci. 21: 294-299.

Cahill, L., Prins, B., Weber, M., and McGaugh, J.L. 1994. $\beta$-adrenergic activation and memory for emotional events. Nature 371: 702-704.

Cahill, L., Babinsky, R., Markowitsch, H.J., and McGaugh, J.L. 1995. The amygdala and emotional memory. Nature 377: 295-296.

Cahill, L., Haier, R.J., Fallon, J., Alkire, M.T., Tang, C., Keator, D., Wu, J., and McGaugh, J.L. 1996. Amygdala activity at encoding correlated with long-term, free recall of emotional information. Proc. Natl. Acad. Sci. 93: 8016-8021.

Calvo, J.M., Simon-Arceo, K., and Fernandez-Mas, R. 1996. Prolonged enhancement of REM sleep produced by carbachol microinjection into the amygdala. Neuroreport 7: 577-580.

Cartwright, R.D., Lloyd, S., Butters, E., Weiner, L., McCarthy, L., and Hancock, J. 1975. Effects of REM time on what is recalled. Psychophysiology 12: 561-568.

de Quervain, D.J., Roozendaal, B., and McGaugh, J.L. 1998. Stress and glucocorticoids impair retrieval of long-term spatial memory. Nature 394: 787-790.

Ekstrand, B.R. 1977. The effect of sleep on human long-term memory. In Neurobiology of sleep and memory (ed. R.R. Drucker-Colin and J.L. McGaugh), pp. 419-438. Academic Press, New York.

Empson, J.A. and Clarke, P.R. 1970. Rapid eye movements and remembering. Nature 227: 287-288.

Foulkes, D. 1962. Dream reports from different stages of sleep. J. Abnorm. Psychol. 65: 14-25.

Fowler, M.J., Sullivan, M.J., and Ekstrand, B.R. 1973. Sleep and memory. Science 179: 302-304.

Goodenough, D.R., Witkin, H.A., Koulack, D., and Cohen, H. 1975. The effects of stress films on dream affect and on respiration and eyemovement activity during Rapid-Eye-Movement sleep. Psychophysiology 12: 313-320.

Grieser, C., Greenberg, R., and Harrison, R.H. 1972. The adaptive function of sleep: The differential effects of sleep and dreaming on recall. $J$. Abnorm. Psychol. 80: 280-286.

Hamann, S.B., Cahill, L., McGaugh, J.L., and Squire, L.R. 1997. Intact enhancement of declarative memory for emotional material in amnesia. Learn. Mem. 4: 301-309.

Hamann, S.B., Ely, T.D., Grafton, S.T., and Kilts, C.D. 1999. Amygdala activity related to enhanced memory for pleasant and aversive stimuli. Nat. Neurosci. 2: 289-293.

Hennevin, E., Maho, C., and Hars, B. 1998. Neuronal plasticity induced by fear conditioning is expressed during paradoxical sleep: Evidence from simultaneous recordings in the lateral amygdala and the medial geniculate in rats. Behav. Neurosci. 112: 839-862.

Horne, J.A. and McGrath, M.J. 1984. The consolidation hypothesis for REM

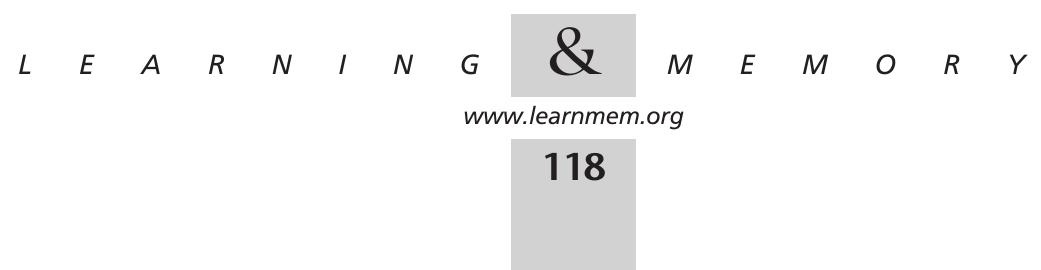


sleep function: Stress and other confounding factors-A review. Biol. Psychol. 18: 165-184.

Jenkins, J.G. and Dallenbach, K.M. 1924. Obliviscence during sleep and waking. Am. J. Psychol. 35: 605-612.

Kirschbaum, C., Wolf, O.T., May, M., Wippich, W., and Hellhammer, D.H. 1996. Stress- and treatment-induced elevations of cortisol levels associated with impaired declarative memory in healthy adults. Life Sci. 58: 1475-1483.

Koulack, D. 1997. Recognition memory, circadian rhythms, and sleep. Percept. Mot. Skills 85: 99-104.

Lewin, I. and Glaubman, H. 1975. The effect of REM deprivation: Is it detrimental, beneficial, or neutral? Psychophysiology 12: 349-353.

Maho, C. and Hennevin, E. 1999. Expression in paradoxical sleep of a conditioned heart rate response. Neuroreport 10: 3381-3385.

Maquet, P., Peters, J., Aerts, J., Delfiore, G., Degueldre, C., Luxen, A., and Franck, G. 1996. Functional neuroanatomy of human rapid-eye-movement sleep and dreaming. Nature 383: 163-166.

Markowitsch, H.J., Calabrese, P., Wurker, M., Durwen, H.F., Kessler, J., Babinsky, R., Brechtelsbauer, D., Heuser, L., and Gehlen, W. 1994. The amygdala's contribution to memory-A study on two patients with Urbach-Wiethe disease. Neuroreport 5: 1349-1352.

McGaugh, J.L., Cahill, L., and Roozendaal, B. 1996. Involvement of the amygdala in memory storage: Interaction with other brain systems Proc. Natl. Acad. Sci. 93: 13508-13514.

Newcomer, J.W., Selke, G., Melson, A.K., Hershey, T., Craft, S., Richards, K., and Alderson, A.L. 1999. Decreased memory performance in healthy humans induced by stress-level cortisol treatment. Arch. Gen. Psychiatry 56: 527-533.

Nofzinger, E.A., Mintun, M.A., Wiseman, M., Kupfer, D.J., and Moore, R.Y 1997. Forebrain activation in REM sleep: An FDG PET study. Brain Res. 770: 192-201.

Plihal, W. and Born, J. 1997. Effects of early and late nocturnal sleep on declarative and procedural memory. J. Cogn. Neurosci. 9: 534-547.

. 1999. Effects of early and late nocturnal sleep on priming and spatial memory. Psychophysiology 36: 571-582.

Plihal, W., Pietrowsky, R., and Born, J. 1999. Dexamethasone blocks sleep induced improvement of declarative memory. Psychoneuroendocrinology 24: 313-331.

Rechtschaffen, A. and Kales, A. 1968. A manual of standardized terminology, techniques and scoring system for sleep stages of buman subjects. Nat. Instit. Health Publication No. 204, Maryland.

Roozendaal, B. 2000. 1999 Curt P. Richter award: Glucocorticoids and the regulation of memory consolidation. Psychoneuroendocrinology 25: 213-238.

Roozendaal, B. and McGaugh, J.L. 1997. Glucocorticoid receptor agonist and antagonist administration into the basolateral but not central amygdala modulates memory storage. Neurobiol. Learn. Mem. 67: 176-179.

Roozendaal, B., Williams, C.L., and McGaugh, J.L. 1999. Glucocorticoid receptor activation in the rat nucleus of the solitary tract facilitates memory consolidation: Involvement of the basolateral amygdala. Eur. J. Neurosci. 11: 1317-1323.

Schürer-Necker, E. 1994. Gedächtnis und Emotion: Zum Einfluss von Emotionen auf das Behalten von Texten. Psychologie Verlags Union, Munich, Germany.

Scrima, L. 1982. Isolated REM sleep facilitates recall of complex associative information. Psychophysiology 19: 252-259.

Smith, C. 1985. Sleep states and learning: A review of the animal literature. Neurosci. Biobehav. Rev. 9: 157-168.

- 1995. Sleep states and memory processes. Behav. Brain Res. 69: $137-145$.

Squire, L.R. 1992. Declarative and nondeclarative memory: Multiple brain systems supporting learning and memory. J.Cogn Neurosci. 4: $232-243$

Stickgold, R., Whidbee, D., Schirmer, B., Patel, V., and Hobson, J. A. 2000. Visual discrimination task improvement: A multi-step process occurring during sleep. J. Cogn. Neurosci. 12: 246-254.

Stones, M.J. 1977. Memory performance after arousal from different sleep stages. Br. J. Psychol. 68: 177-181.

Thase, M.E. 1998. Depression, sleep, and antidepressants. J. Clin. Psychiatry 59: 55-65.

Tilley, A.J. and Empson, J.A. 1978. REM sleep and memory consolidation. Biol. Psychol. 6: 293-300.

Tilley, A. and Warren, P. 1983. Retrieval from semantic memory at different times of day. J. Exp. Psychol. Learn. Mem. Cogn. 9: 718-724.

Vertes, R.P. and Eastman, K.E. 2000. The case against memory consolidation in REM sleep. Behav. Brain Sci. (in press).

Yaroush, R., Sullivan, M.J., and Ekstrand, B.R. 1971. Effect of sleep on memory. II. Differential effect of the first and second half of the night. J. Exp. Psychol. 88: 361-366.

Received September 13, 2000; accepted in revised form January 4, 2001. 


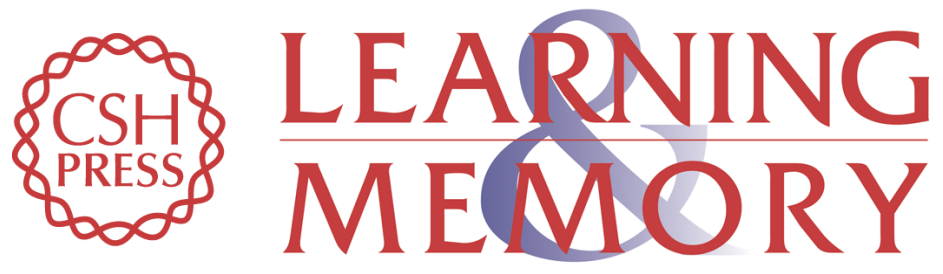

\section{Emotional Memory Formation Is Enhanced across Sleep Intervals with High Amounts of Rapid Eye Movement Sleep}

Ullrich Wagner, Steffen Gais and Jan Born

Learn. Mem. 2001, 8:

Access the most recent version at doi:10.1101//m.36801

References This article cites 46 articles, 6 of which can be accessed free at: http://learnmem.cshlp.org/content/8/2/112.full.html\#ref-list-1

License

Email Alerting Receive free email alerts when new articles cite this article - sign up in the box at the Service top right corner of the article or click here. 